\title{
Squash vein yellowing virus Infection of Vining Cucurbits and the Vine Decline Response
}

Craig G. Webster, United States Department of Agriculture-Agricultural Research Service (USDA-ARS), U.S. Horticultural Research Laboratory, Fort Pierce, FL 34945 USA; Chandrasekar S. Kousik, USDA-ARS, U.S. Vegetable Laboratory, Charleston, SC 29414 USA; William W. Turechek, USDA-ARS, U.S. Horticultural Research Laboratory, Fort Pierce, FL 34945 USA; Susan E. Webb, University of Florida, Department of Entomology and Nematology, Gainesville, FL 32611 USA; Pamela D. Roberts, Department of Plant Pathology, Southwest Florida Research and Education Center, University of Florida, Immokalee, FL 34142 USA; and Scott Adkins, USDA-ARS, U.S. Horticultural Research Laboratory, Fort Pierce, FL 34945 USA

\begin{abstract}
Webster, C. G., Kousik, C. S., Turechek, W. W., Webb, S. E., Roberts, P. D., and Adkins, S. 2013. Squash vein yellowing virus infection of vining cucurbits and the vine decline response. Plant Dis. 97:1149-1157.

The responses of a diverse group of vining cucurbits to inoculation with Squash vein yellowing virus (SqVYV) were determined. For the first time, Cucurbita maxima, Cucumis dipsaceus, and Cucumis metuliferus were observed to develop necrosis and plant death similar to the SqVYVinduced vine decline in watermelon (Citrullus lanatus var. lanatus). The majority of cucurbits inoculated, however, either exhibited no symptoms of infection, or developed relatively mild symptoms such as vein yellowing of upper, noninoculated leaves. All inoculated plants were sectioned and tested for the presence of SqVYV. The virus was widely distributed in mature, fruit-bearing cucurbits with over $72 \%$ of plant

sections testing positive for SqVYV by tissue-blot and/or reverse transcription-polymerase chain reaction. Plants of several cucurbits, including a wild citron (Citrullus lanatus var. citroides), were symptomless and had a decreased frequency of virus infection of vine segments compared to susceptible vining cucurbits, indicating a higher level of resistance. However, no significant relationship between the frequency of infection or virus distribution within plants and the symptom response was observed. These results demonstrate that a diverse group of cucurbits may decline when infected with SqVYV, and suggest that widespread distribution of virus within the plant is not the sole cause of decline.
\end{abstract}

Watermelon (Citrullus lanatus var. lanatus) production in Florida has been severely impacted by the ipomovirus Squash vein yellowing virus (SqVYV; 2). SqVYV was recently introduced to the United States (18) and is whitefly-transmitted (Bemisia tabaci (Gennadius); 17) in a semipersistent manner. SqVYV causes viral watermelon vine decline, which is characterized by a rapid wilt and death of infected vines (2). Fruits from infected plants often display necrotic areas in the rind and flesh degradation, which reduces quality and marketability. The disease appears most frequently at, or just before, harvest and often leads to near-complete losses. The severe symptoms induced by SqVYV are typical of plant infection by several species within the genus Ipomovirus including Cucumber vein yellowing virus (CVYV), which causes necrosis of watermelon fruit, and sudden plant death of melons (11) and highly susceptible cucumber genotypes (14). Cassava brown streak virus (CBSV) and Ugandan cassava brown streak virus (UCBSV) cause necrosis of stems and tuberous roots of cassava $(15,19)$.

Watermelon and other cucurbit crops in southwest and west-central Florida have been infected with SqVYV most growing seasons since 2003, causing epidemics of varying severity. In 2004, individual grower losses of 50 to $100 \%$ in infected watermelon fields cost the industry an estimated 60 to 70 million dollars (7). The virus has subsequently been detected in Indiana (5), Georgia (18),

Corresponding author: S. Adkins, E-mail: scott.adkins@ ars.usda.gov

Mention of a trademark, warranty, proprietary product or vendor does not constitute a guarantee by the U.S. Department of Agriculture and does not imply its approval to the exclusion of other products or vendors that also may be suitable.

Accepted for publication 13 March 2013.

http://dx.doi.org/10.1094/PDIS-01-13-0076-RE

This article is in the public domain and not copyrightable. It may be freely reprinted with customary crediting of the source. The American Phytopathological Society, 2013. and South Carolina (C. S. Kousik and S. Adkins, unpublished), although its appearance has been sporadic in these states.

All known experimental and natural hosts of SqVYV are within the family Cucurbitaceae (2-4). In contrast to the severe symptoms in watermelon, the symptoms of SqVYV infection in other known cucurbit hosts are much milder. Cucurbit crops such as squash, pumpkin, cucumber, and melon typically develop vein yellowing on inoculated and upper, noninoculated leaves (2). Cucurbit weeds, such as smellmelon (Cucumis melo var. dudaim; 4) and Balsam apple (Momordica charantia; 3), often display no symptoms of infection but can act as reservoirs for virus spread into cultivated plants (3). The wilt and necrosis induced in watermelon has not been reported in any other host of the virus. Screening of watermelon germplasm has demonstrated that all tested commercial cultivars are susceptible to infection by SqVYV and the resulting vine decline (2; S. Adkins and C. S. Kousik, unpublished data). However, several Citrullus plant introductions have been identified that display moderate resistance to SqVYV, including a line of Citrullus lanatus var. lanatus, which is being used as a breeding line to develop resistance to the virus $(9,10)$.

Chlorosis, vein yellowing, and/or epinasty of the youngest leaves are typical early symptoms of SqVYV infection, but it is not known whether the virus is directly or indirectly causing these changes. SqVYV infection of watermelon usually leads to detectable amounts of virus in the crown, peduncle, and fruit (16) rather than the vine tip, where symptoms first appear. The distribution of SqVYV within other cucurbit hosts has not yet been elucidated. In this study, we examined the responses of a diverse group of vining cucurbits to inoculation with SqVYV, and the distribution of SqVYV within these cucurbits to further explore the causes of SqVYV-induced vine decline.

\section{Materials and Methods}

Virus and plant sources. An isolate of SqVYV originally collected from watermelon in southwest Florida was used for all experiments (2). It was maintained by mechanical inoculation in squash (Cucurbita pepo) 'Prelude II' (Seminis Seeds, Oxnard, CA) 
and watermelon 'Crimson Sweet' using $20 \mathrm{mM}$ sodium phosphate buffer ( $\mathrm{pH} 7.0)$ containing $0.1 \%(\mathrm{wt} / \mathrm{vol})$ sodium sulfite and $1 \%$ (wt/vol) Celite.

Commercially available seeds were used for the majority of cucurbits tested (Johnny's Selected Seeds, Winslow, ME; Willhite Seeds, Pooleville, TX) with the exception of the wild citron (originally collected in central Florida and provided by Don L. Hopkins, University of Florida), Balsam apple (originally collected in southwest Florida; 3), and horned melon and Seminole pumpkin (provided by Michael Bausher, USDA-ARS). These cucurbits are referred to as cultivars in this manuscript for ease of discussion, although we realize these are not officially recognized cultivars of the respective species.

Plants were grown in a temperature-controlled greenhouse under natural lighting with a daytime high temperature of $30^{\circ} \mathrm{C}$. The insecticide imidacloprid (Admire Pro, Bayer Crop Science, Research Triangle Park, NC) and fungicide quinoxyfen (Quintec, Dow Agrosciences, Indianapolis, IN) were applied as needed to prevent insect and fungal infestation.

Molecular methods for SqVYV detection. Tissue-blot nucleic acid hybridization assays and reverse transcription-polymerase chain reaction (RT-PCR) were used to detect SqVYV within cucur- bit samples. Tissue print blots were made from vines of freshly cut cucurbit tissue blotted on positively charged nylon membranes (Roche, Indianapolis, IN) and hybridized with a digoxigenin labeled probe of a 1,071-bp region of the coat protein (CP) of SqVYV. Immobilization, hybridization, and chemiluminescent development of membranes were as previously described (16).

Total RNA was extracted from 100 to $130 \mathrm{mg}$ of tissue with Trizol Reagent (Invitrogen Life Sciences, Carlsbad, CA) using the recommended protocol, suspended in RNase-free water, and quantified using a Nanodrop spectrophotometer (Nanodrop Technologies, Wilmington, DE). First strand cDNA was synthesized using $500 \mathrm{ng}$ total RNA and a broad-spectrum potyvirus $3^{\prime}$ terminus primer (6). A 1,071-bp region of the SqVYV CP gene was amplified by PCR using primers and methods as previously described (3). All products were visualized on $1 \%$ (wt/vol) agarose gels (Amresco, Solon, $\mathrm{OH}$ ) stained with ethidium bromide.

Greenhouse evaluation of young vining cucurbits. Young plants (17 days old, without fruit) of 41 cucurbits representing 16 species (Table 1) were inoculated with SqVYV and examined for symptoms every 6 to 7 days for 22 days postinoculation (dpi) to rapidly screen their response to SqVYV. Subsequently, a second set of five cucurbits, selected for their response to SqVYV in the ini-

Table 1. Symptom response and presence of Squash vein yellowing virus infection in young (39 day old) greenhouse grown vining cucurbits

\begin{tabular}{|c|c|c|c|c|c|}
\hline Type & Species & Cultivar & Symptoms $^{w}$ & Symptom incidence $^{x}$ & Virus presence $^{y}$ \\
\hline Watermelon & Citrullus lanatus var. lanatus & Crimson Sweet & $-/ \mathrm{SWN}$ & $5 / 5$ & + \\
\hline Citron $^{z}$ & Citrullus lanatus var. citroides & Citron & $-1-$ & $0 / 8$ & + \\
\hline Bur Gherkin & Cucumis anguria & Hedgehog & $-/ \mathrm{MVY}$ & $2 / 3$ & + \\
\hline Gourd & Cucumis dipsaceus & Wooly Bear & $-1-$ & $0 / 8$ & + \\
\hline Teasel Gourd & Cucumis dipsaceus & Prickles & $-/ \mathrm{SWN}$ & $8 / 8$ & + \\
\hline Cantaloupe & Cucumis melo & Ambrosia Hybrid & $-/ \mathrm{MVY}$ & $1 / 8$ & + \\
\hline Cantaloupe & Cucumis melo & Athena & $-/ \mathrm{VY}$ & $7 / 8$ & + \\
\hline Cantaloupe & Cucumis melo & Jumbo Hales Best & $-/ S V Y$ & $4 / 8$ & + \\
\hline Cantaloupe & Cucumis melo & PMR-45 & $-1-$ & $0 / 8$ & + \\
\hline Cantaloupe & Cucumis melo & Topmark & $-/ \mathrm{VY}$ & $7 / 8$ & + \\
\hline Cantaloupe & Cucumis melo & Sweet n' Early & $-/ \mathrm{MVY}$ & $2 / 8$ & + \\
\hline Crenshaw & Cucumis melo & Lily & $-/ V Y$ & $8 / 8$ & + \\
\hline Galia & Cucumis melo & Diplomat & -/SVY, CL & $6 / 7$ & + \\
\hline Honeydew & Cucumis melo & Honeydew & $-/ \mathrm{VY}$ & $1 / 7$ & + \\
\hline Honeydew & Cucumis melo & Honey Yellow & $-/ \mathrm{SVY}$ & $8 / 8$ & + \\
\hline Horned Melon & Cuситis metuliferus & Horned Melon & $-/ \mathrm{SWN}$ & $7 / 7$ & + \\
\hline Cucumber & Cucumis sativus & Green Long & $-/ \mathrm{VY}$ & $8 / 8$ & - \\
\hline Cucumber & Cucumis sativus & Marketmore 76 & $-/ T V Y$ & $2 / 8$ & - \\
\hline Cucumber & Cucumis sativus & Poinsett 76 & $-/ \mathrm{TVY}$ & $4 / 8$ & - \\
\hline Cucumber & Cucumis sativus & Straight 8 & $-/ T V Y$ & $4 / 8$ & - \\
\hline Cucumber & Cucumis sativus & Straight 9 & -/TVY & $3 / 8$ & + \\
\hline Pumpkin & Cucurbita maxima & Jarrahdale & -/VY, W & $5 / 8$ & + \\
\hline Pumpkin & Cucurbita maxima & Big Max & -/VY, CL, W & $4 / 4$ & + \\
\hline Hubbard Squash & Cucurbita maxima & Blue Ballet & -/VY & $8 / 8$ & + \\
\hline Buttercup Squash & Cucurbita maxima & Buttercup Green & -/VY, CL, SWN & $4 / 8$ & + \\
\hline Seminole Pumpkin & Cucurbita moschata & Seminole Pumpkin & $-/ \mathrm{VY}$ & $3 / 3$ & - \\
\hline Tropical Pumpkin & Cucurbita moschata & La Estrella & $-1-$ & $0 / 8$ & + \\
\hline Butternut Squash & Cucurbita moschata & Waltham & -/VY, CL & $7 / 8$ & + \\
\hline Pumpkin & Сисигbita реро & Baby Boo & -/SVY & $5 / 8$ & + \\
\hline Pumpkin & Сисurbita pepo & Jack O’lantern & CL/VY & $8 / 8$ & + \\
\hline Pumpkin & Cucurbita pepo & Pink Banana Jumbo & $-/ C L, L D$ & $3 / 8$ & + \\
\hline Spaghetti Squash & Сисurbita реро & Spaghetti & $-/ \mathrm{VY}$ & $7 / 8$ & + \\
\hline Delicata Squash & Cucurbita pepo & Sweet Dumpling & -/SVY, CL & $8 / 8$ & + \\
\hline Waxgourd & Benincasa hispida & Jade & $-/ \mathrm{CL}$ & $6 / 8$ & + \\
\hline Bottle Gourd & Lagenaria siceraria & Birdhouse & $-/ M V Y$ & $4 / 8$ & + \\
\hline Bottle Gourd & Lagenaria siceraria & Gourd Dipper & $-/ \mathrm{CL}$ & $7 / 8$ & + \\
\hline Luffa & Luffa cylindrica & Green Splendor & $-1-$ & $0 / 8$ & - \\
\hline Edible Gourd & Luffa acutangula & Rama & $-/ \mathrm{MVY}$ & $6 / 8$ & + \\
\hline Bitter Gourd & Momordica charantia & Bitter Gourd & $-1-$ & $0 / 8$ & + \\
\hline Tinda Gourd & Praecitrullus fistulosus & Tinda & $-1-$ & $0 / 8$ & + \\
\hline Snake Gourd & Trichosanthes anguina & Polo & $-1-$ & $0 / 7$ & + \\
\hline
\end{tabular}

${ }^{\mathrm{w}}$ Symptoms on inoculated and upper, noninoculated leaves indicated to left and right of slash, respectively; -, no symptoms; CL, chlorotic lesions; LD, leaf deformation; MVY, mild vein yellowing; VY, vein yellowing; SVY, severe vein yellowing; SWN, systemic wilt and necrosis; TVY, transient vein yellowing; W, wilt.

${ }^{x}$ Number of plants with symptoms of virus infection and total number of plants inoculated indicated to left and right of slash, respectively.

${ }^{y}$ Diagnostic test results for virus presence at 22 days postinoculation. A ' + ' indicates that at least one of the samples tested positive by tissue-blot and/or RTPCR.

${ }^{\mathrm{z}}$ Seeds were collected from wild plants growing in Florida. 
tial screen, was inoculated with SqVYV and observed every 6 to 7 days for up to 49 dpi to allow a longer period for virus symptoms to develop. In both experiments, eight plants of each cucurbit were mechanically inoculated with virus, and two plants were mock inoculated with buffer only at the two to three true leaf stage and monitored for symptoms. Presence of SqVYV was determined at 22 or 49 dpi by one or more of the following methods: (i) visual assessment of symptoms typical of SqVYV infection including necrosis, vein yellowing, and petiole collapse; (ii) tissue-blot nucleic acid hybridization assay; or (iii) RT-PCR.

Greenhouse evaluation of mature vining cucurbits. To examine the response to SqVYV inoculation of mature plants bearing fruit, 21 vining cucurbits in 12 species were vertically trellised on soft cotton strings to allow production of larger plants with fruit, more typical of field grown plants as described elsewhere (1). $\mathrm{Cu}$ curbits were selected to represent crop and weed species, and the diversity of symptoms observed in the initial experiments on young plants without fruit. Plants were trimmed to a single stem, and flowers were pollinated by hand to produce, in most cases, a single fruit per plant. The cotyledons and six lower-most pairs of true leaves were mechanically inoculated with SqVYV when plants were 50 to 64 days old, an age when watermelon plants with fruit are observed to decline (1). Plants were inoculated again at 7 and
14 days after the first inoculation to prevent escapes. Visual ratings of plant symptoms were made at 14 to $28 \mathrm{dpi}$, when plants were 64 to 92 days old. In addition, approximately 2-cm-long vine segments were cut at the crown, fruit peduncle (if present), vine tip, and vine sections of increasing distance from the crown for a total of eight samples per plant. Virus presence in each sample was determined by tissue-blot for all samples, and by RT-PCR for at least one complete plant of each cucurbit tested. All samples of a given cucurbit were analyzed by RT-PCR when inconsistencies between tissue-blot and RT-PCR methods were observed.

Field evaluation of vining cucurbits. Selected cucurbits from greenhouse studies were tested for response to SqVYV in field experiments in fall 2009 and spring 2010 at the Southwest Florida Research and Education Center, University of Florida in Immokalee. Cucurbits selected for both field trials included 'Jarrahdale,' 'Blue Ballet,' 'Buttercup Green,' 'Prickles,' and citron, with 'Crimson Sweet' included as a susceptible control. Five plants of each cucurbit grown in 10-liter pots were transplanted at 28 days old into a raised bed fumigated with methyl bromide (50:50) applied in-bed at $112 \mathrm{~kg} \mathrm{ha}^{-1} 14$ days before transplanting on 6 October 2009 or 15 March 2010 . The bed was $0.81 \mathrm{~m}$ wide with a $3.7-\mathrm{m}$ center, and covered with white or black plastic mulch in the fall or spring, respectively. Guidelines established by the University of
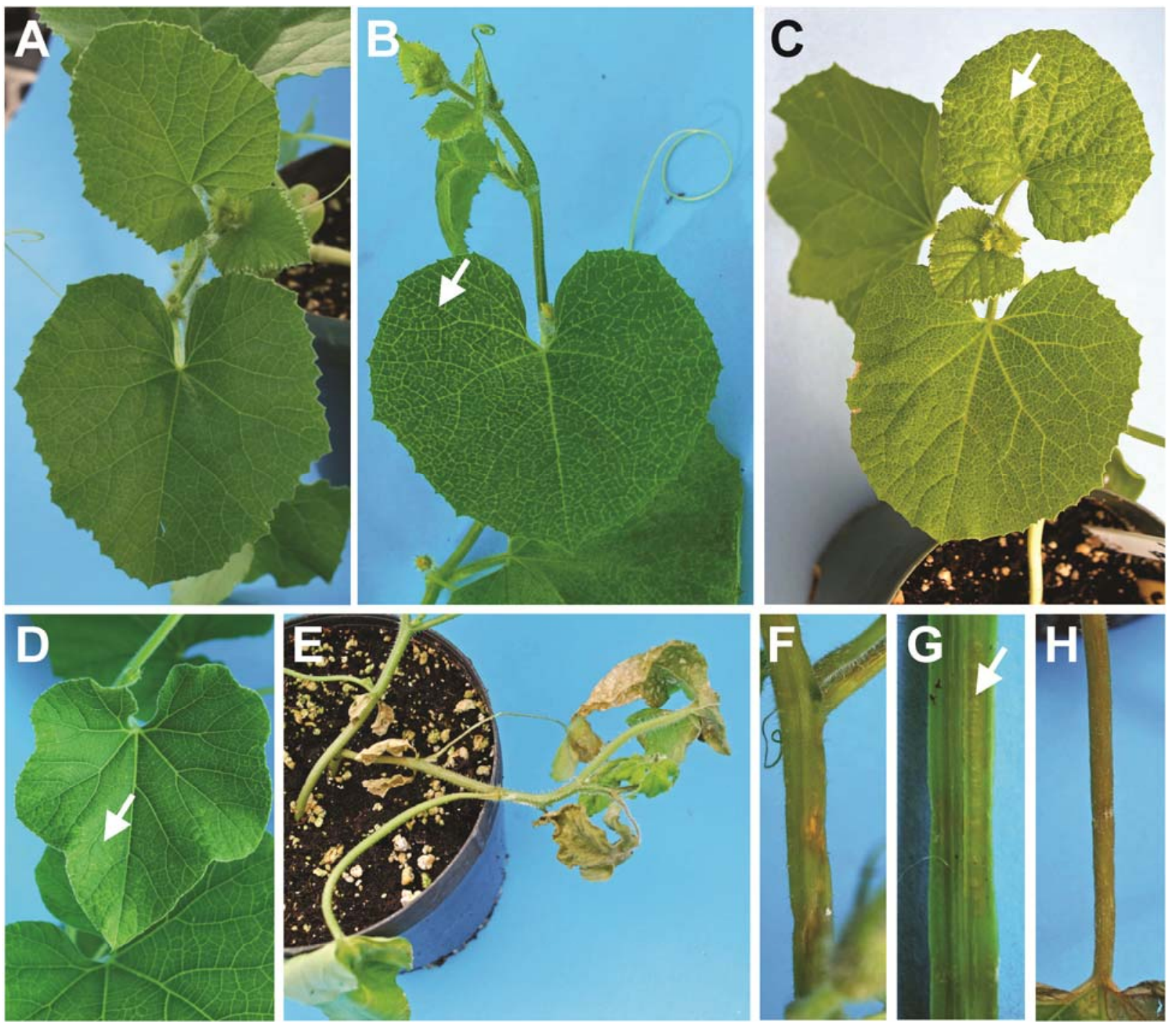

Fig. 1. Diversity of symptoms typical of Squash vein yellowing virus infection of young (39 day old) vining cucurbits at 22 days postinoculation. A, Asymptomatic vine tip and lower leaves of a mock-inoculated Cucumis melo 'PMR-45' shown for comparison. Vein yellowing (see arrows) of upper, noninoculated leaves of Cucumis melo, B, 'Ambrosia Hybrid' and C, 'Jumbo Hales Best.' D, Lagenaria siceraria 'Gourd Dipper' with chlorotic lesions (arrow) on upper, noninoculated leaf. E, Systemic wilt, necrosis, and complete plant collapse in Cucumis dipsaceus 'Prickles.' F, Cucurbita maxima 'Buttercup Green' with extensive external and G, internal necrosis along the vine of the plant. Arrow points to a necrotic vascular bundle. H, Cucurbita maxima 'Jarrahdale' showing petiole necrosis and collapse. 
Florida/IFAS were followed for land preparation, fertility, irrigation, and weed management (13). No insecticides were applied for whitefly management to facilitate whitefly transmission of SqVYV.

Five replicate blocks, each containing a single plant of each cucurbit in a randomized order, were planted in a single $100-\mathrm{m}$ row with 2-m spacing between blocks. A 28-day-old SqVYV-infected 'Zucchini Hybrid' squash (Burpee Seeds, Warminster, PA) was planted at the end of each block to serve as the initial inoculum source. Virus was spread by whiteflies under natural conditions. Symptoms of virus infection were recorded every 6 to 7 days. Plants were collected for virus testing when necrosis and wilting were observed. Virus distribution was determined from eight $2-\mathrm{cm}-$ long segments dissected from a single fruit-bearing vine of each plant (as described above for greenhouse studies on mature, fruitbearing plants) and tested for virus presence by tissue-blot (all plants) or RT-PCR (selected plants as detailed in Results).

Analysis of virus symptoms and distribution. A generalized linear mixed model (GLMM) was used to determine the effect of cucurbit cultivar on the frequency of virus detection in greenhouse experiments using the SAS Procedure GLIMMIX. The percentage of plant parts $(n=8)$ testing positive for virus was treated as the dependent variable, cucurbit cultivar as a fixed effect, and block as a random effect specifying an identity link function and Gaussian (normal) error distribution. Treatment differences were obtained using the LSMEANS statement with the LINES option. Model fit was assessed based on an analysis of the residuals and a normal probability plot. Although various transformations were applied to the dependent variable, none improved the overall fit relative to the nontransformed variable, thus this model was retained.

Cultivars were grouped into response categories based on their response to SqVYV inoculation (Table 2). Logistic regression was used to determine the effect of response category and plant part (i.e., position within the plant) on the incidence of infection (i.e., plant parts were either infected or not) using the SAS procedure LOGISTIC. Response category and plant part were treated as factors. Treatment differences were determined for significant effects using the LINES option in the LSMEANS statement (only available with the GLM parameterization). The interaction between the two factors was not significant; thus this term was removed from the model and data reanalyzed with just the main effects.

To analyze the effect of cucurbit cultivar on virus distribution in field experiments, the binary test responses (i.e., plant parts were either infected or not) were analyzed with logistic regression using the SAS procedure LOGISTIC. The data were analyzed individually by year treating cucurbit cultivar and position within the plant as factors. As above, treatment differences were determined for significant effects using the LINES option in the LSMEANS statement, and the interaction was dropped from the model because the interaction between the two factors was not significant.

\section{Results}

Young vining cucurbit response to SqVYV inoculation. Expression of symptoms and virus distribution in vining cucurbits following inoculation with SqVYV were determined for 41 different cucurbit cultivars (Table 1). Symptoms of SqVYV infection were observed on the upper, noninoculated leaves of 33 cucurbits at $22 \mathrm{dpi}$, whereas the corresponding mock-inoculated plants displayed no symptoms of virus infection (Fig. 1A). The most common symptom among cucurbits tested (27 of 41) was for upper leaves, not including the vine tip, to display vein yellowing (e.g., 'Ambrosia Hybrid,' Fig. 1B; 'Jumbo Hales Best,' Fig. 1C). Eight cucurbits showed chlorotic lesions on upper, noninoculated leaves (e.g., 'Gourd Dipper,' Fig. 1D). 'Jack O'lantern' was unique in that chlorotic lesions were observed on inoculated leaves. Interestingly, none of the eight citron plants displayed any symptoms of virus infection including systemic wilt or necrosis.

The systemic wilt and necrosis characteristic of SqVYV infection of watermelon was observed in the control 'Crimson Sweet' plants. By 22 dpi, the upper, noninoculated leaves displayed wilting and yellowing, and the vine showed necrotic lesions from the crown to the tip. Chlorosis, wilting of leaves, and necrosis of vine tissue (particularly near the crown) were observed in 'Prickles' (Fig. 1E), 'Buttercup Green' (Fig. 1F and G), and horned melon similar to typical SqVYV symptoms in watermelon. In contrast to these severe symptoms, the other Cucurbita maxima cultivars tested ('Jarrahdale' and 'Big Max') developed necrosis of petioles, which led to wilting of upper, noninoculated leaves (Fig. 1H), and 'Blue Ballet' and 'Hedgehog' displayed only vein yellowing on upper, noninoculated leaves.

The presence of SqVYV was determined by tissue-blot for all plants and by RT-PCR for all sections of at least one plant of each cucurbit (Table 1, Fig. 2) as described below. SqVYV infection was confirmed in cucurbits that developed vein yellowing or wilting, although the virus was not uniformly distributed throughout

Table 2. Squash vein yellowing virus symptom response and percent infection in mature, fruit-bearing (64 to 92 day old) greenhouse grown vining cucurbits

\begin{tabular}{|c|c|c|c|c|}
\hline Response category & Species & Cultivar & Symptoms $^{x}$ & $\%$ Infection $^{y}$ \\
\hline \multirow[t]{3}{*}{ Resistant } & Benincasa hispida & Jade & - & $0 \mathrm{e}$ \\
\hline & Cucurbita moschata & La Estrella & - & $0 \mathrm{e}$ \\
\hline & Citrullus lanatus var. citroides & Citron $^{z}$ & - & $5 \mathrm{e}$ \\
\hline \multirow[t]{7}{*}{ Asymptomatic } & Cucumis melo & Honey Yellow & - & $90 \mathrm{abc}$ \\
\hline & Cucumis melo & Lily & - & 85 abcd \\
\hline & Cucumis melo & Diplomat & - & $63 \mathrm{~d}$ \\
\hline & Cucumis sativus & Green Long & - & $93 \mathrm{abc}$ \\
\hline & Lagenaria siceraria & Birdhouse & - & $93 a b c$ \\
\hline & Momordica charantia & Balsam Apple ${ }^{z}$ & - & $70 \mathrm{bcd}$ \\
\hline & Trichosanthes anguina & Polo & - & 83 abcd \\
\hline \multirow[t]{6}{*}{ Symptomatic } & Cucumis melo & Jumbo Hales Best & VY & $98 \mathrm{a}$ \\
\hline & Cucumis melo & Topmark & VY & $97 \mathrm{ab}$ \\
\hline & Cucumis anguria & Hedgehog & VY & $63 \mathrm{~cd}$ \\
\hline & Cucurbita pepo & Baby Boo & VY & $98 \mathrm{a}$ \\
\hline & Cucurbita pepo & Jack O'lantern & VY & $90 \mathrm{abc}$ \\
\hline & Cucurbita moschata & Waltham & VY & $93 \mathrm{abc}$ \\
\hline \multirow[t]{5}{*}{ Decline } & Citrullus lanatus var. lanatus & Crimson Sweet & PN, RN, VN, W & $93 a b c$ \\
\hline & Cucurbita maxima & Jarrahdale & PN, VN, VY, W & $60 \mathrm{~d}$ \\
\hline & Cucurbita maxima & Blue Ballet & VN, VY, W & 75 abcd \\
\hline & Cucurbita maxima & Buttercup Green & VN, VY, W & 75 abcd \\
\hline & Cucumis dipsaceus & Prickles & PN, VY, W & $98 \mathrm{a}$ \\
\hline
\end{tabular}

${ }^{x}$ Symptoms of virus infection at 14 to 28 days postinoculation: -, no symptoms; PN, petiole necrosis; RN, rind necrosis; VN, vine necrosis; VY, vein yellowing; $\mathrm{W}$, wilting.

${ }^{y}$ Percentage of plant segments in which virus was detected. Eight samples per plant were tested by tissue-blot with selected samples further tested by RTPCR. Cultivars sharing the same letter are not significantly different according to Fishers LSD $(P \leq 0.05)$. Differences are based on least squared means.

${ }^{\mathrm{z}}$ Seeds were collected from wild plants growing in Florida. 
plants, with the tips often showing no evidence of infection (e.g., Fig. 2B, C, and D). Balsam apple showed no hybridization on tissue-blots; however, RT-PCR demonstrated infection. Seminole pumpkin developed symptoms; however, no virus was detectable by tissue-blot, presumably due to a false negative reaction as seen with Balsam apple. 'Blue Ballet,' 'Buttercup Green,' and 'Jarrahdale' showed hybridization in some, but not all, mock-inoculated plants (Fig. 2E and F); however, no SqVYV was detected by RTPCR in the mock-inoculated plants. Tissue-blots of both mock- and SqVYV-inoculated plants of several cucurbits including 'Birdhouse' (Fig. 2G), 'Gourd Dipper,' 'Tinda,' 'Honey Yellow,' 'Spaghetti,' 'Sweet Dumpling,' 'La Estrella,' 'Big Max,' 'Jade,' 'Polo,' and 'Green Splendor' showed hybridization signal with the SqVYV CP probe; however, RT-PCR testing detected no virus in these cucurbits (in this or any subsequent experiment), and the hybridization signal was likely due to a nonspecific reaction. In all subsequent experiments, all samples of Balsam apple, 'Blue Ballet,' 'Buttercup Green,' 'Jarrahdale,' 'Birdhouse,' 'Jade,' and 'Polo' were tested by RT-PCR. Asymptomatic infections of Balsam apple, 'PMR-45,' and 'La Estrella' were found (Tables 1 and 2), although SqVYV was again not uniformly distributed. No virus was detected in five other cucurbits, including four of the five cucumbers tested, which showed transient symptoms as previously observed (2).

A relatively slow development of symptoms was seen in some cucurbits (e.g., 'Jarrahdale') compared to the 'Crimson Sweet' controls. At $22 \mathrm{dpi}$, systemic wilt and necrosis was observed in 'Crimson Sweet' inoculated with SqVYV. Cucurbits 'Jarrahdale,' 'Blue Ballet,' 'Buttercup Green,' horned melon, and 'Prickles' showed milder symptoms including some necrosis of petioles. When a second set of these cucurbits was maintained for $49 \mathrm{dpi}$, all developed extensive necrosis throughout the vine and all leaves succumbed to wilt and necrosis. Virus presence in symptomatic plants was confirmed by tissue-blot and RT-PCR. These data demonstrated that non-watermelon cucurbits tested here (e.g., 'Jarrahdale') required a longer period of time for systemic wilt and necrosis to develop compared to watermelon (e.g., 'Crimson Sweet').

Mature vining cucurbit response to SqVYV inoculation. Based on symptoms (Fig. 3) and virus presence, the 21 cucurbits tested were assigned to one of four response categories (resistant, asymptomatic, symptomatic, or decline; Table 2). In total, $72 \%$ (584 of 813) of the segments tested were positive for SqVYV (Table 3$)$. No symptoms of virus infection were observed in 10 cucurbits; however, virus was detected in eight of these cucurbits including two crown samples of citron (Table 2). Since no further movement of the virus was detected in citron and no symptoms developed (Fig. 3G, H, and I), it was categorized as resistant along with 'Jade' and 'La Estrella'.

Diverse virus symptoms were observed in the remaining cucurbits, mostly vein yellowing of upper, noninoculated leaves one to two leaves back from the vine tip. This included 'Jumbo Hales Best' and 'Topmark,' which had distinct vein yellowing in contrast to other asymptomatic cucurbits ('Honey Yellow,' 'Lily,' and 'Diplomat'). Some Cucurbita pepo ('Baby Boo' and 'Jack O'lantern') and Cucurbita moschata ('Waltham') cultivars also displayed vein yellowing of upper, noninoculated leaves; however, these symptoms were more severe and also included some distortion of leaves. Necrosis of the petioles and vine was observed in the remaining cucurbits (Fig. 3B and E) along with wilting, particularly at the vine tip (Fig. 3A and D). Necrosis was localized within vascular bundles in the vines and peduncles (Fig. 1G). Five cucurbits displayed this symptom: Cucurbita maxima ('Jarrahdale,' 'Blue Ballet,' and 'Buttercup Green'), Cucumis dipsaceus ('Prickles'), and the 'Crimson Sweet' control. Necrotic spots in the fruit rind typical of SqVYV infection of watermelon were observed in 'Crimson Sweet' (Fig. 3C) but not in any other cucurbit tested, including those in the decline category ('Blue Ballet,' 'Buttercup Green,' and 'Prickles'; Fig. 3F). No fruit were produced on 'Jarrahdale' in greenhouse experiments despite repeated pollination attempts.

A high percentage of vine segments were infected for most cucurbits tested by tissue-blot or RT-PCR. Apart from citron, 'Jade,'
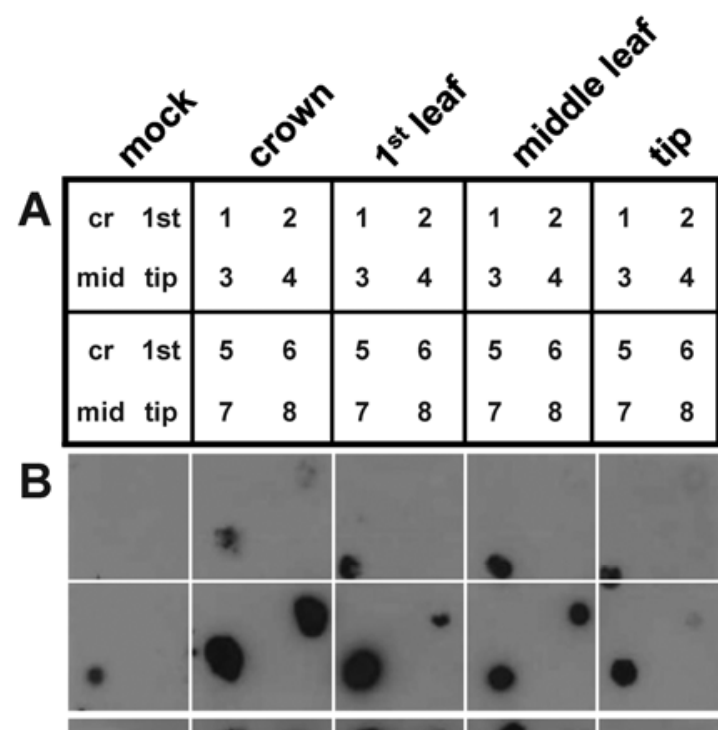

C

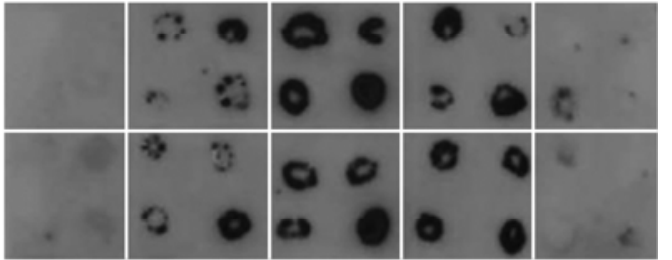

D

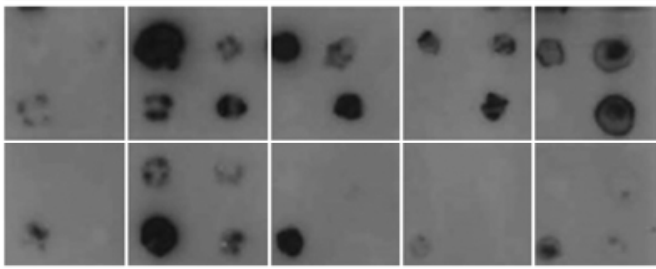

$\mathbf{E}$

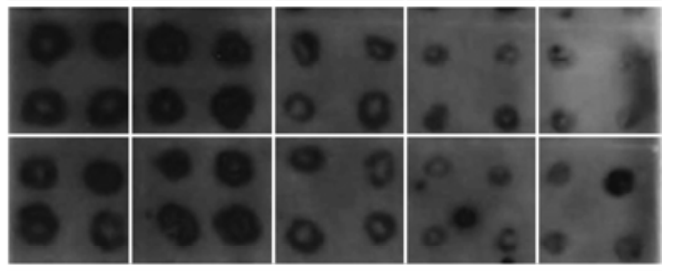

$\mathbf{F}$

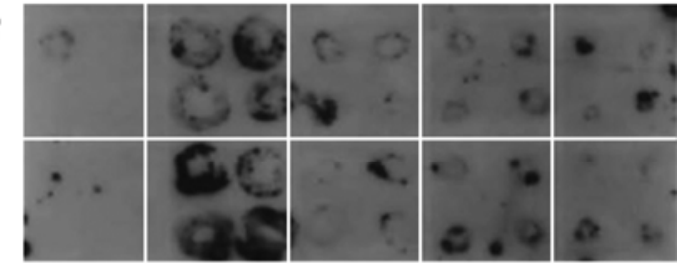

G

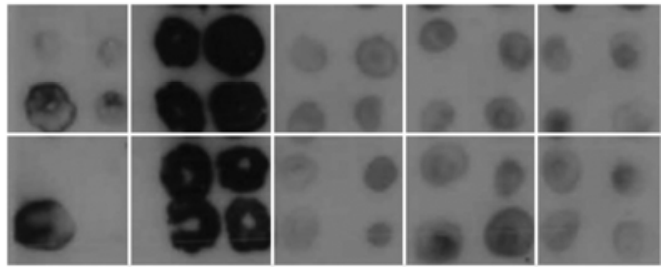

Fig. 2. Tissue blot nucleic acid hybridization detection of Squash vein yellowing virus (SqVYV) in vining cucurbits. A, Diagram of tissue-blots showing two mock(left) and eight SqVYV-inoculated plants (right) ordered by sample location of crown (cr), petiole of first noninoculated leaf (1st), petiole of middle leaf (mid), and vine tip (tip). SqVYV-inoculated plants were numbered from 1 to 8 . B, Citrullus lanatus var. lanatus 'Crimson Sweet' with SqVYV detected in SqVYV-inoculated but not mockinoculated plants. C, Cucurbita pepo 'Jack O'lantern' with SqVYV detected throughout all plants, except for the tip and mock-inoculated plants. D, Cucumis melo 'Jumbo Hales Best' with incomplete SqVYV distribution and noninfected mock inoculated plants. E and F, Cucurbita maxima 'Blue Ballet' inoculated with SqVYV with apparent virus signal in some (E) but not all $(F)$ mock-inoculated plants. G, Lagenaria siceraria 'Birdhouse Gourd' with apparent virus signal in the middle leaf of mock-inoculated plants. 

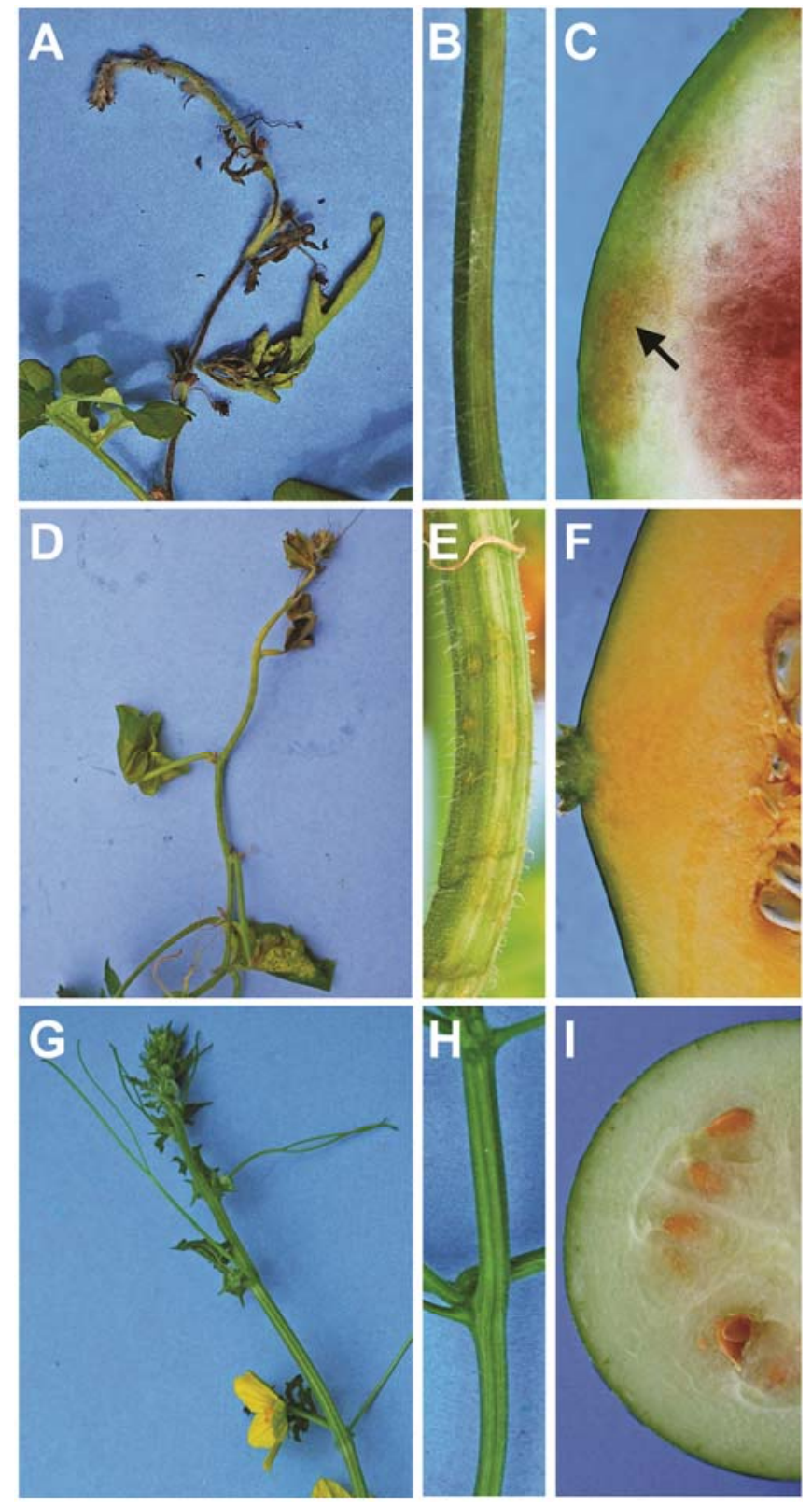

Fig. 3. Tip, vine, and fruit symptoms of Squash vein yellowing virus in mature, fruitbearing (64 to 92 day old) vining cucurbits at 14 to 28 days postinoculation. Citrullus lanatus var. lanatus 'Crimson Sweet' A, tip, B, vine, and C, fruit showing wilt and/or necrosis, including of the rind (arrow). Cucurbita maxima 'Buttercup Green' D, tip with SqVYV-induced wilt and necrosis, similar to that observed in watermelon, $\mathbf{E}$, vine showing necrosis, and $\mathbf{F}$, asymptomatic fruit. Citrullus lanatus var. citroides citron $\mathbf{G}$, tip, $\mathbf{H}$, vine, and $\mathbf{I}$, asymptomatic fruit. and 'La Estrella,' 60 to $98 \%$ of segments for all other cucurbits were infected (Table 2). Analysis indicated that these three resistant cucurbits were significantly different $(P<0.05)$ from all other cucurbits, and no distinction between the remaining response categories (asymptomatic, symptomatic, and decline) and percentage of infection could be made (Table 2) as indicated by the overlapping groupings of these three response categories (a to d; Table 2).

Relationship of virus symptoms to distribution. Virus incidence in vine segments was used to compare the distribution of SqVYV within plants (Table 3). No virus was detected in the three cucurbits in the resistant category ('La Estrella,' 'Jade,' and citron [except for two infected crown samples]). Cucurbits in the other three response categories (asymptomatic, symptomatic, and decline) all showed high levels of SqVYV infection with widespread virus distribution. The frequency of virus detection was lower in the vine tips $(64 \%)$ than in the crown and sections of the vine (72 to $76 \%)$; however, this was only weakly significant $(P=0.0713)$. There were also no significant differences in the distribution of virus throughout each response category with similar frequencies of virus detection seen at each sample location for the asymptomatic, symptomatic, and decline categories (Table 3 ). The percentage of plant segments infected was significantly higher $(P<$ 0.0001 ) for cucurbits in the three response categories containing infected plants than for cucurbits in the resistant category.

Field evaluations of vining cucurbits. Symptoms of decline in non-watermelon cucurbits in the field mirrored those observed in the greenhouse (Fig. 4). Symptoms of necrosis and wilt leading to plant collapse were observed, particularly in the three Cucurbita maxima cultivars ('Buttercup Green' [Fig. 4A], 'Blue Ballet' [Fig. 4B], and 'Jarrahdale') and the 'Crimson Sweet' controls. The first symptoms appeared on 'Crimson Sweet' as little as 14 days posttransplanting, and plants were collected 28 to 42 days post-transplanting when severe symptoms of decline were seen. As in the greenhouse, the development of symptoms of decline in Cucurbita maxima cultivars was typically delayed by 14 to 28 days compared to 'Crimson Sweet.' In contrast, 'Prickles' (Fig. 4C) and horned melon did not develop necrosis along the vines, but by the end of the trial (56 days post-transplanting) the petioles and leaves of the plants were necrotic. Virus infection was confirmed by tissue-blot and RT-PCR. As in the greenhouse study, rind necrosis only developed in 'Crimson Sweet' fruits but not in those of any of the other cucurbits, including 'Jarrahdale,' that produced no fruit in greenhouse trials.

As determined in greenhouse studies (Tables 2 and 3), citron plants had a more limited distribution of SqVYV and showed milder symptoms of infection, with only 47 and $0 \%$ of segments infected in 2009 and 2010, respectively (Table 4). Interestingly, symptoms of downy mildew infection were noted on three citron plants in 2009, and were most severe in the plants with the highest virus incidence. In comparison, 'Crimson Sweet' had high rates of infection with 100 and $72 \%$ of segments infected in 2009 and 2010 , respectively, with the percentage of vine segments infected in other declining cucurbits being similarly high (Table 4). As in the greenhouse experiments, the lower percentage of citron vine

Table 3. Distribution of Squash vein yellowing virus within mature, fruit-bearing (64 to 92 day old) greenhouse grown vining cucurbits

\begin{tabular}{lcccccc}
\hline Response category $^{\mathbf{w}}$ & Crown & Lower vine $^{\mathbf{x}}$ & Peduncle & Upper vine $^{\mathbf{x}}$ & Tip & \% Infection $^{\mathbf{y}}$ \\
\hline Resistant & $2 / 15$ & $0 / 30$ & $0 / 14$ & $0 / 46$ & $0 / 15$ & $1.7 \mathrm{a}$ \\
Asymptomatic & $30 / 35$ & $62 / 73$ & $28 / 30$ & $89 / 107$ & $21 / 35$ & $82 \mathrm{~b}$ \\
Symptomatic & $23 / 27$ & $55 / 59$ & $22 / 25$ & $71 / 76$ & $24 / 27$ & $91 \mathrm{c}$ \\
Decline & $22 / 25$ & $46 / 58$ & $15 / 19$ & $57 / 73$ & $20 / 25$ & $80 \mathrm{~b}$ \\
\% infection $^{\mathrm{z}}$ & $75 \mathrm{a}$ & $74 \mathrm{a}$ & $74 \mathrm{a}$ & $72 \mathrm{a}$ & $64 \mathrm{~b}$ & 72 \\
\hline
\end{tabular}

${ }^{\mathrm{w}}$ Based on symptom expression when inoculated with Squash vein yellowing virus. See Table 2 for cucurbits included in each response category.

${ }^{x}$ Number of infected segments and total number of segments tested indicated to left and right of slash, respectively, of all vine sections between the crown and peduncle (lower) or peduncle and tip (upper).

${ }^{y}$ Percentage of segments infected within a response category. Percentages sharing same letter are not significantly different $(P \leq 0.05)$ according to mean separation test. Differences are based on least squared means.

${ }^{\mathrm{z}}$ Percent infection of a single type of plant segment. Percentages sharing same letter are not significantly different $(P \leq 0.0713)$ according to mean separation test. Differences are based on least squared means. 
segments infected was statistically significant for both years $(P<$ $0.05)$, with the remaining declining cucurbits again mostly forming overlapping groupings with some significant differences seen (e.g., 'Prickles' in 2010; Table 4). The distribution of virus within plants was not determined to be significant in either year $(P=0.1410$ and 0.4227 for 2009 and 2010, respectively).

\section{Discussion}

The vining cucurbits tested in this study were assigned to four response categories based on symptoms and presence of SqVYV. While the majority of cultivars responded to infection with typical vein yellowing of upper, noninoculated leaves, several cucurbits developed symptoms closely resembling those of SqVYV-induced watermelon vine decline. Although all commercial watermelon cultivars previously examined have succumbed to vine decline $(2,9)$, this is the first report of other cucurbits declining in a similar fashion. Interestingly, plant genus alone was not sufficient to predict the SqVYV response category of an individual cucurbit. For instance, the Citrullus, Cucurbita, and Cucumis genera contained all declining cucurbits but also contained cucurbits (e.g., Citrullus lanatus var. citroides, Cucurbita pepo, and Cucumis sativus) in the other three response categories (resistant, asymptomatic, and symptomatic). The genetic differences which are involved in resistance to SqVYV in these cucurbits are not known and warrant further testing. Hosts other than cucurbits may also warrant testing, as the closely related CVYV has several noncucurbit hosts $(8,12)$; however, this was beyond the scope of the current study.

No SqVYV-induced decline was observed in previous testing of other cucurbits, including Cucurbita maxima 'Big Max' (2). Our current results indicate a likely reason, namely that a longer period of time is required for wilt and necrosis to develop in Cucurbita maxima compared to watermelon. This delay in vine decline symp-
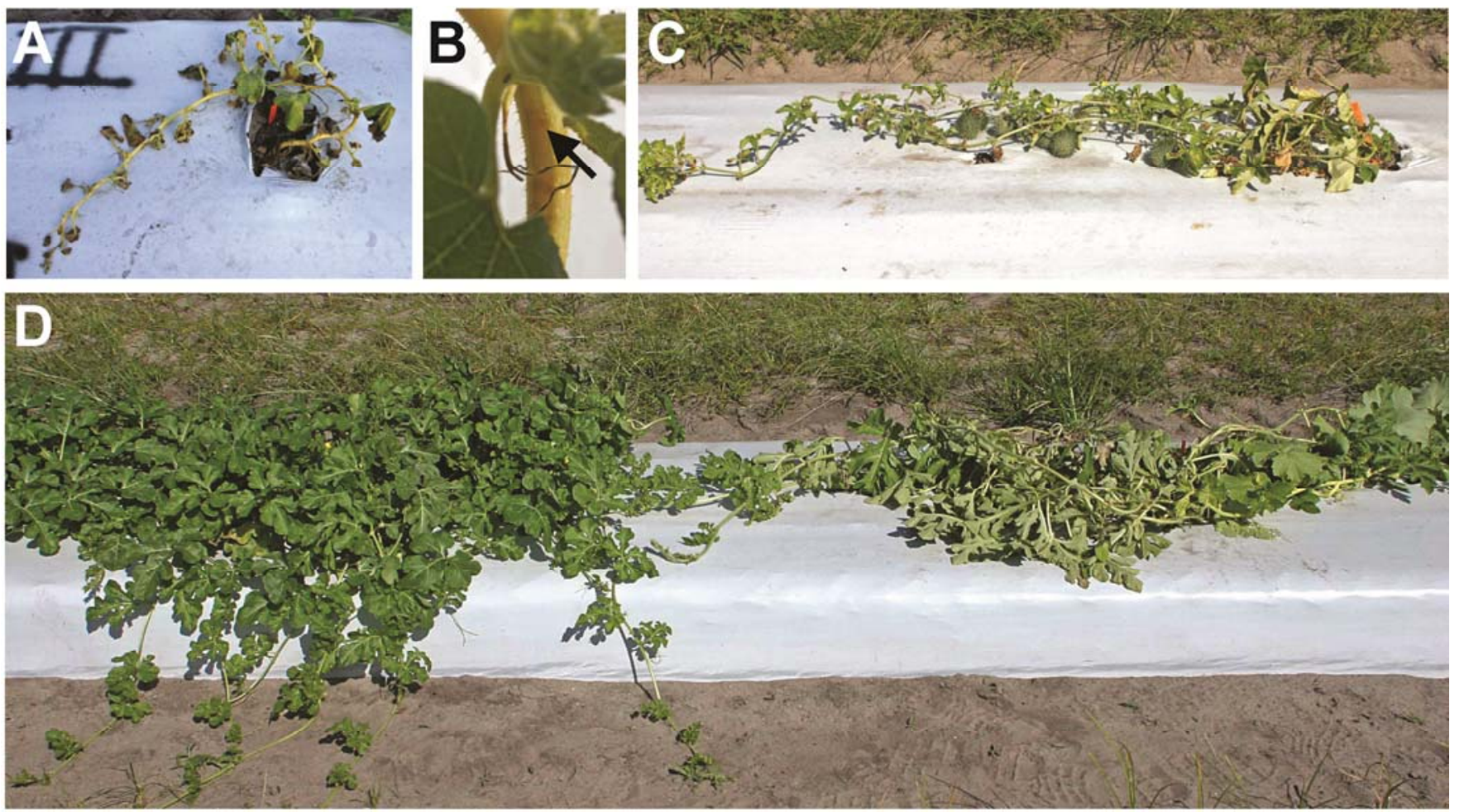

Fig. 4. Symptoms of Squash vein yellowing virus in vining cucurbits in a field trial in fall 2009. A, Cucurbita maxima 'Buttercup Green' with systemic wilt and necrosis. B, Cucurbita maxima 'Blue Ballet' showing necrosis along vine (arrow). C, Cucumis dipsaceus 'Prickles' with systemic wilt and necrosis. D, Asymptomatic Citrullus lanatus var. citroides citron (left) and Citrullus lanatus var. lanatus 'Crimson Sweet' (right) with systemic wilt and necrosis typical of watermelon vine decline.

Table 4. Distribution of Squash vein yellowing virus within field-grown vining cucurbits

\begin{tabular}{|c|c|c|c|c|c|c|c|}
\hline Year & Cultivar $^{x}$ & Crown & Lower vine $^{y}$ & Peduncle & Upper vine $^{\mathrm{y}}$ & Tip & $\%$ Infection $^{\mathrm{z}}$ \\
\hline \multirow[t]{6}{*}{2009} & Crimson Sweet & $5 / 5$ & $16 / 16$ & $4 / 4$ & 9/9 & $6 / 6$ & $100 \mathrm{a}$ \\
\hline & Blue Ballet & $5 / 5$ & $15 / 15$ & $4 / 4$ & $10 / 11$ & $4 / 5$ & $95 \mathrm{a}$ \\
\hline & Jarrahdale & $5 / 5$ & $13 / 15$ & $2 / 4$ & $11 / 11$ & $5 / 5$ & $90 \mathrm{a}$ \\
\hline & Prickles & $2 / 3$ & $5 / 5$ & $13 / 18$ & $1 / 3$ & $1 / 3$ & $69 \mathrm{bc}$ \\
\hline & Buttercup Green & $4 / 5$ & $13 / 17$ & $1 / 2$ & $7 / 11$ & $3 / 5$ & $70 \mathrm{c}$ \\
\hline & Citron & $4 / 5$ & $7 / 15$ & $4 / 7$ & $4 / 8$ & $0 / 5$ & $47 \mathrm{~d}$ \\
\hline \multirow[t]{6}{*}{2010} & Crimson Sweet & $3 / 4$ & $9 / 12$ & $1 / 2$ & $8 / 10$ & $2 / 4$ & $72 \mathrm{~b}$ \\
\hline & Blue Ballet & $4 / 4$ & $2 / 6$ & $3 / 3$ & $3 / 15$ & $4 / 4$ & $47 \mathrm{c}$ \\
\hline & Jarrahdale & $1 / 5$ & $7 / 12$ & $5 / 7$ & $8 / 11$ & $2 / 5$ & $58 \mathrm{bc}$ \\
\hline & Prickles & $3 / 3$ & $7 / 7$ & $7 / 7$ & $3 / 4$ & $3 / 3$ & $96 \mathrm{a}$ \\
\hline & Buttercup Green & $4 / 5$ & $4 / 9$ & $1 / 7$ & $13 / 14$ & $3 / 5$ & $63 \mathrm{bc}$ \\
\hline & Citron & $0 / 5$ & $0 / 9$ & $0 / 5$ & $0 / 17$ & $0 / 4$ & $0 \mathrm{~d}$ \\
\hline
\end{tabular}

' Cucurbit cultivar: 'Crimson Sweet' (Citrullus lanatus var. lanatus); 'Blue Ballet,' 'Jarrahdale,' and 'Buttercup Green' (Cucurbita maxima); 'Prickles' (Cucumis dipsaceus); and citron (Citrullus lanatus var. citroides).

${ }^{y}$ Number of infected segments and total number of segments tested indicated to left and right of slash, respectively, of all vine sections tested between the crown and peduncle (lower) or peduncle and tip (upper).

${ }^{\mathrm{z}}$ Percentage of segments infected within each cucurbit. Percentages sharing same letter are not significantly different $(P<0.0001)$ according to mean separation test. Differences are based on least squared means. 
tom appearance was observed for both young (requiring up to 49 dpi) and mature, fruit-bearing plants (requiring up to $21 \mathrm{dpi}$ ). The observation of SqVYV-induced vine decline in Cucurbita maxima, and also Cucurbita metuliferus and Cucumis dipsaceus (which are not widely grown in the United States), indicate that SqVYV may be of concern to a wider range of cucurbits than previously known. Some Cucurbita maxima cultivars are grown in Florida (13), although they are more commonly grown in northern states. However, vine decline has not been reported in Cucurbita maxima or other cucurbits in Florida, and despite a single detection of SqVYV in Indiana in 2005 (5), the virus has not been found since (S. Adkins, unpublished data) and is likely not established there. The lack of reported SqVYV detection in Cucurbita maxima may be due to the lack of symptoms in fruits (with no rind necrosis in either greenhouse or field grown plants) and decline symptoms being delayed compared to watermelon. Early infection of young Cucurbita maxima plants could be more serious, as suggested by the decline of young plants in our greenhouse studies, although SqVYV-induced decline of young watermelon plants in commercial fields has not been reported (1). In northern states, cold winters likely limit survival of cucurbit weed or volunteer crop reservoirs for the virus to pass from one growing season to the next. Taken together, this suggests that SqVYV-induced vine decline of Cucurbita maxima may be rare, but these and other cucurbits may serve as potential reservoirs for SqVYV, as we have previously demonstrated for Balsam apple (3) and smellmelon (4).

The SqVYV-inoculated citron showed no symptoms of virus infection (Fig. 3) in contrast to the decline induced in cultivated Citrullus species. This was observed with both young and older, fruitbearing plants grown in the greenhouse and field (Fig. 4). In our experiments, the frequency of virus infection was always lower in citron than in watermelons and other cucurbits, which decline in both greenhouse (Tables 2 and 3) and field experiments (Table 4). This includes the fall 2009 field trial when $47 \%$ of citron segments were virus infected compared to 69 to $100 \%$ of the remaining cucurbits (Table 4). While the mechanism of SqVYV resistance is not yet known, it is unlikely to result from whitefly resistance because mechanically inoculated greenhouse plants also showed resistance to the virus. Additional research is required to yield commercially useful resistance. One potential avenue of future research is to compare SqVYV titer within a selection of cucurbits, since viral accumulation is related to CVYV resistance in cucumber (14).

Tissue-blot detection of SqVYV in watermelon is currently the most high throughput detection method for use in watermelon vine decline studies. However, our current work with a wide range of cucurbits has shown some of the limitations of tissue-blots, most notably the false positives in mock-inoculated plants of some cucurbits (e.g., Lagenaria siceraria 'Birdhouse'; Fig. 2G) and false negatives in SqVYV-inoculated plants of other cucurbits (e.g., Balsam apple; Table 2), determined to be infected by RT-PCR. For this reason, RT-PCR is a more reliable means of SqVYV detection in a wider range of cucurbits than watermelon, including 'Birdhouse,' Balsam apple, 'La Estrella,' and 'Jade.' Further analysis of this and additional data sets will be useful to evaluate the relative effectiveness of SqVYV detection methods.

SqVYV was detected in a high percentage of vine segments in greenhouse and field grown cucurbits expressing symptoms (Tables 2, 3, and 4). This indicates that the symptom response, including necrosis and decline of some Cucurbita and Cucumis species, was not solely due to the percentage of vine segments infected. A high frequency of infected vine segments was detected in cucurbits with symptoms (e.g., 'Jumbo Hales Best') or without symptoms (e.g., 'Green Long'). Only citron had a significantly different percentage of vine segments infected in both greenhouse and field experiments. The continuum of percent infection of vine segments in most cucurbits indicates that watermelon and other cucurbits do not suffer from vine decline because of widespread distribution of the virus along affected vines.

An increased probability of detecting SqVYV near the crown of watermelon plants was previously reported (16). SqVYV was often detected at or near the crown of all cucurbits tested in the greenhouse and the field from the current study (Table 4), although a higher frequency of virus detection at vine tips was observed than in previous studies (16). Greenhouse experiments examining physiological effects of SqVYV infection on watermelon similarly demonstrated a wide distribution of virus within watermelon plants, especially in younger plants and when fruits were absent (1). Previous field plant distribution studies examined plants naturally infected by whiteflies from virus reservoirs in the environment (16) and likely became infected closer to harvest (at an older age) in contrast to the high inoculum levels in our current greenhouse studies. Plant growth stage, presence of fruit, and/or feeding preference of the whitefly vector all likely influence within-plant SqVYV distribution. The single time points chosen in our current experiments were not designed to examine such differences. However, in watermelon, Cucurbita maxima, Cucumis metuliferus, and Cucumis dipsaceus, our results demonstrate that infection with SqVYV led to necrosis and plant death at both plant ages tested.

The appearance of necrosis along vascular bundles (Fig. 1), and wilting and apparent water stress symptoms observed in SqVYVinfected watermelons indicate a restriction in the transport of water is causing the sudden and systemic wilt and necrosis in affected plants. A reduction in the fresh weight of SqVYV-infected watermelons (1) supports this conclusion. Cross-sections in tissue-blots typically revealed SqVYV RNA localized in the vascular bundles throughout the vine (Fig. 2C and F). SqVYV inclusions have previously been reported in parenchyma and companion cells in phloem of watermelon and squash leaf tissue (2). Our observation of necrosis along the vines of declining cucurbits (e.g., Figs. 1F and G, and $3 \mathrm{~B}$ and $\mathrm{E}$ ) is likely due to the death of virus-infected phloem cells, which may ultimately lead to the observed collapse of the entire plant. Accumulation of SqVYV virions or virion components within phloem tissues may cause these cells to die in a few but not all cucurbits. SqVYV distribution was not significantly reduced in declining cucurbits (Table 2), suggesting that vascular tissues collapse after movement of the virus along the vine. Similar necrosis has been reported in limited plant species following infection by other ipomoviruses, including CVYV in melon (Cucumis melo; 11), and CBSV and UCBSV in cassava (Mannihot esculenta; 19). The mechanism of this decline requires further study with the lack of necrosis and systemic wilt and decline in closely related cucurbit species identified here, allowing comparisons between these responses to be made.

In summary, this study has identified a wider range of cucurbits that decline when infected with SqVYV, including Cucurbita maxima, Cucumis dipsaceus, and Cucumis metuliferus. In contrast, a wild citron was identified that developed no symptoms of infection with SqVYV, except for field plants grown in 2009 when downy mildew was present. However, in all greenhouse and field experiments, a significantly lower percentage of the citron vines was infected with SqVYV than other susceptible cucurbits, and therefore this citron might be useful in ongoing efforts to breed SqVYV resistance in watermelon. Finally, no significant association was detected between symptom response and either the distribution of virus within the plant or the percentage of vine segments infected. This indicates that neither widespread distribution of SqVYV within infected plants nor localization of SqVYV to a particular region of the plant is the sole cause of vine decline. The search continues for other, presently unknown, factors responsible for the decline induced by SqVYV infection.

\section{Acknowledgments}

We thank Carrie Vanderspool, Bridget Burns, Jeff Smith, Nicole Miller, Reid Lewis, Rod Systma, and David Ballesteros for their excellent technical assistance, and Don Hopkins and Michael Bausher for providing seeds. Financial support was provided in part by USDA CSREES SCRI grant 2008-04890 and the National Watermelon Association.

\section{Literature Cited}

1. Adkins, S., McCollum, T. G., Albano, J. P., Kousik, C. S., Baker, C. A., Webster, C. G., Roberts, P. D., Webb, S. E., and Turechek, W. W. 2013. 
Physiological effects of Squash vein yellowing virus infection on watermelon. Plant Dis. 97:1137-1148.

2. Adkins, S., Webb, S. E., Achor, D., Roberts, P. D., and Baker, C. A. 2007. Identification and characterization of a novel whitefly-transmitted member of the family Potyviridae isolated from cucurbits in Florida. Phytopathology 97:145-154.

3. Adkins, S., Webb, S. E., Baker, C. A., and Kousik, C. S. 2008. Squash vein yellowing virus detection using nested polymerase chain reaction demonstrates that the cucurbit weed Momordica charantia is a reservoir host. Plant Dis. 92:1119-1123.

4. Adkins, S., Webster, C. G., Baker, C. A., Weaver, R., Rosskopf, E. N., and Turechek, W. W. 2009. Detection of three whitefly-transmitted viruses infecting the cucurbit weed Cucumis melo var. dudaim in Florida. Plant Health Progress doi:10/1094/PHP-2009-1118-01-BR

5. Egel, D. S., and Adkins, S. 2007. Squash vein yellowing virus identified in watermelon (Citrullus lanatus) in Indiana. Plant Dis. 91:1056.

6. Gibbs, A., and Mackenzie, A. 1997. A primer pair for amplifying part of the genome of all potyvirids by RT-PCR. J. Virol. Methods 63:9-16.

7. Huber, M. 2006. Taking vital vines. Citrus Veg. Mag. 70:22-24.

8. Janssen, D., Ruiz, L., Velasco, L., Segunda, E., and Cuadrado, I. M. 2002. Non-cucurbitaceous weed species shown to be natural hosts of Cucumber vein yellowing virus in south-eastern Spain. Plant Pathol. 51:797.

9. Kousik, C. S., Adkins, S., Turechek, W. W., and Roberts, P. D. 2009. Sources of resistance in U.S. plant introductions to watermelon vine decline caused by Squash vein yellowing virus. HortScience 44:256-262.

10. Kousik, C. S., Adkins, S., Turechek, W. W., Webster, C. G., and Roberts, P. D. 2012. 392291-VDR, a watermelon germplasm line with resistance to Squash vein yellowing virus-caused watermelon vine decline (WVD). HortScience. 47:1805-1807.
11. Louro, D., Quinot, A., Neto, E., Fernandes, J. E., Marian, D., Vecchiati, M., Caciagli, P., and Vaira, A. M. 2004. Occurrence of Cucumber vein yellowing virus in cucurbitaceous species in southern Portugal. Plant Pathol. 53:241.

12. Morris, J., Steel, E., Smith, P., Boonham, N., Spence, N., and Barker, I. 2006. Host range studies for Tomato chlorosis virus and Cucumber vein yellowing virus transmitted by Bemisia tabaci (Gennadius). Eur. J. Plant Pathol. 114:265-273.

13. Olson, S. M., Simonne, E. H., Stall, W. M., Roberts, P. D., Webb, S. E., and Smith, S. A. 2010. Cucurbit production in Florida. Pages 83-105 in: Vegetable Production Handbook for Florida, 2010-2011. S. M. Olson and B. Santos, eds. University of Florida IFAS Extension, Gainesville.

14. Pićo, B., Villar, C., and Nuez, F. 2003. Screening Cucumis sativus landraces for resistance to cucumber vein yellowing virus. Plant Breed. 122:426-430.

15. Storey, H. H. 1936. Virus diseases of East African plants. VI. A progress report on studies of the diseases of cassava. East Afr. Agric. J. 2:34-39.

16. Turechek, W. W., Kousik, C. S., and Adkins, S. 2010. Distribution of four viruses in single and mixed infections within infected watermelon plants in Florida. Phytopathology 100:1194-1203.

17. Webb, S. E., Adkins, S., and Reitz, S. R. 2012. Semipersistent whitefly transmission of Squash vein yellowing virus, causal agent of viral watermelon vine decline. Plant Dis. 96:839-844

18. Webster, C. G., and Adkins, S. 2012. Low genetic diversity of Squash vein yellowing virus in wild and cultivated cucurbits in the U.S. suggests a recent introduction. Virus Res. 163:520-527.

19. Winter, S., Koerbler, M., Stein, B., Pietruszka, A., Paape, M., and Butgereitt, A. 2010. Analysis of cassava brown streak viruses reveals the presence of distinct virus species causing cassava brown streak disease in East Africa. J. Gen. Virol. 91:1365-1372. 